\title{
Morphological Characteristics, Nutritional Quality, and Bioactive Constituents in Fruits of Two Avocado (Persea americana) Varieties from Hainan Province, China
}

\author{
Yu $\mathrm{Ge}^{1, \dagger}$, Xiongyuan $\mathrm{Si}^{2}{ }^{2,}$, Jianqiu $\mathrm{Cao}^{3}$, Zhaoxi Zhou ${ }^{1}$, Wenlin Wang ${ }^{4} \&$ Weihong $\mathrm{Ma}^{1}$ \\ ${ }^{1}$ Haikou Experimental Station, Chinese Academy of Tropical Agricultural Sciences, Hainan, China \\ ${ }^{2}$ Biotechnology Center, Anhui Agricultural University, Anhui, China \\ ${ }^{3}$ College of Horticulture and Landscape Architecture, Hainan University, Hainan, China \\ ${ }^{4}$ Guangxi South Subtropical Agricultural Science Research Institute, Guangxi, China \\ Correspondence: Yu Ge, Haikou Experimental Station, Chinese Academy of Tropical Agricultural Sciences, \\ Hainan, China. Tel: 86-0898-6677-0005. E-mail: geyu@catas.cn \\ Weihong Ma, Haikou Experimental Station, Chinese Academy of Tropical Agricultural Sciences, Hainan, China. \\ Tel: 86-0898-6677-3067. E-mail: zjwhma@163.com
}

Received: November 20, $2016 \quad$ Accepted: December 20, $2016 \quad$ Online Published: January 15, 2017

doi:10.5539/jas.v9n2p8 URL: http://dx.doi.org/10.5539/jas.v9n2p8

${ }^{\dagger}$ These authors contributed equally to this work.

\begin{abstract}
We studied the morphological characteristics, nutritional quality, and the bioactive compounds in fruits of two avocado accessions, RN-7 and RN-8, produced in Hainan province, China. Edible and non-edible parts of the fruit (pulp and seed) were compared to evaluate their possible contribution to improve the sustainability of the food and pharmaceutical industries. The basic characteristics evaluated were moisture, ash, total lipid, fatty acid composition, soluble sugars, titratable acid, soluble protein, and minerals. We also measured the concentrations of six types of bioactive compounds; total phenolics, flavonoids, tannin, ascorbic acid, tocopheryl acetate, and carotenoids. Our analyses of the nutritional compositions demonstrated that the pulp of the RN-7 and RN-8 proved to be rich in moisture, total lipid, and soluble protein. The seed, in turn, had higher soluble sugar, titratable acidity, sodium, potassium, calcium, iron, copper, and zinc contents. Other nutritional compositions (ash, magnesium, and manganese) had little differences between the pulp and seed of avocado fruit. With regard to the contents of bioactive compounds, the seed was superior to the pulp in the contents of total phenolics, flavonoids, and tannin. Regarding the concentrations of ascorbic acid, tocopheryl acetate, and total carotenoids, the highest values were found in the pulp. The results of fatty acid compositions displayed that the palmitic, palmitoleic, stearic, oleic, and linoleic acid contents of the pulp were higher than those of the seed, while myristic and arachic acid had higher contents in the seed.
\end{abstract}

Keywords: chemical compositions, pulp, seed

\section{Introduction}

Avocado (Persea americana Mill.) belongs to the botanical family Lauraceae, and originated in Mexico, or possibly Central or South America (Dreher \& Davenport, 2013). Avocado fruit is rich in lipids, proteins, minerals, vitamins, and other nutritients and active ingredients (Dreher \& Davenport, 2013; Galvão et al., 2014). The lipid content can comprise $15-30 \%$ of the fresh weight of the fruit depending on the cultivar, season, and growing conditions (Meyer \& Terry, 2008). It is remarkable is that the lipids in avodado fruit contain $\sim 60 \%$ monounsaturated fatty acids and $\sim 13 \%$ essential fatty acids such as linoleic and linolenic acid, which are beneficial to human cardiovascular health (Villa-Rodríguez et al., 2011; Giraldo \& Moreno-Piraján, 2012; Dreher \& Davenport, 2013; Donetti \& Terry, 2014; Pedreschi et al., 2016). In contrast to lipid content, the sugar content of avocado fruit is relatively low (Meyer \& Terry, 2008, 2010). Hence, avocado fruit is generally recommended for people suffering from diabetes because it is a high-energy food. Natural antioxidants, in particular flavonoids and other groups of polyphenols, have potential uses in the pharmaceutical and food 
industries because of their many benefits such as reducing the risk of inflammatory diseases and preventing lipid oxidation (Chen et al., 2014). Avocado fruit contains more phenolic compounds than other kinds of tropical and subtropical fruits (Kosinska et al., 2012; Vinha et al., 2013; Chen et al., 2014). Recent studies have also demonstrated that avocado contains other bioactive compounds that are equally beneficial to human heath, such as vitamins and phytochemicals (vitamin C, vitamin E, carotene, etc.) and minerals (phosphorus, sodium, potassium, calcium, and magnesium) (Dreher \& Davenport, 2013; Vinha et al., 2013).

It is widely recognized that the avocado was initially introduced to China in 1918 (Papademetriou, 2000). Hundreds of avocado varieties were also introduced to China from the USA, Israel, and other countries in the late 1950s (He, 2012; Zhang et al., 2015). Traditional selective breeding and hybridization were widely used and continue to this day at the Chinese Academy of Tropical Agricultural Sciences, resulting in the introduction of more than a dozen high-quality avocado varieties (Zhang et al., 2015). At present, several Chinese superior avocado varieties are widely grown in various regions of Hainan province.

The avocado cultivars 'Fuerte' and 'Hass' are the most commercially valuable varieties and account for up to two-thirds of the avocado production around the world. Hence, most studies of avocado quality characteristics use these two cultivars (Ashton et al., 2006; Meyer \& Terry, 2008, 2010; Hurtado-Fernandez et al., 2011, 2014, 2015; Rodríguez-Carpena et al., 2011; Villa-Rodríguez et al., 2011; Reddy et al., 2012; Donetti \& Terry, 2014; Ferreyra et al., 2016; Pedreschi et al., 2016; Rohman et al., 2016). However, no similar studies on Chinese native avocado varieties have been published to date. Thus, the objectives of this study were to determine the morphological characteristics, nutritional quality, and the compositions of bioactive compounds in the fruits of two avocado varieties, RN-7 and RN-8. These two varieties have been recommended by the Chinese Academy of Tropical Agricultural Sciences, located in the province of Hainan, China. The non-edible seeds were also investigated in order to evaluate their potential use as cheap waste production for the food, pharmaceutical, and dermocosmetic industries.

\section{Materials and Methods}

\subsection{Plant Material, Reagents, and Sample Preparation}

Fruits of the two avocado accessions, RN-7 and RN-8, used in the present study were obtained from the garden of the avocado germplasm resource affiliated with the Chinese Academy of Tropical Agricultural Sciences in Danzhou city, Hainan province, China (North latitude: $19^{\circ} 11^{\prime}$, East longitude: $108^{\circ} 50^{\prime}$ ). Eighteen mature fruits of each accession were collected and selected for their firmness and absence of mechanical damage and visible decay. The fruits were immediately transported in standard polystyrene foam boxes that are used for export packaging and held at $5-6{ }^{\circ} \mathrm{C}$ until they reached the laboratory. The pulp and seeds were separated from the fruits, homogenized using a kitchen blender, and stored at $4{ }^{\circ} \mathrm{C}$ until analysis, which was conducted within one week.

\subsection{Morphological Characteristics and Physicochemical Assays}

Fruit skin color was determined from eight points on the equatorial area of each fruit per accession using a SPAD-502 Plus colorimeter. Values were obtained in CIELAB scale ( $\left.L^{*}, a^{*}, b^{*}\right)$, and Hue angle and chroma values were calculated. Length, width, and weight were measured for each fruit and its seed. The measurements were performed on nine fruits of each accession.

\subsection{Quantification of Nutritional Compositions}

\subsubsection{Moisture Assay}

Fresh avocado pulp and seed samples (5 g) were homogenized separately using a high-speed homogenizer and placed in an air dry oven (GZX-9146 MBE, Shanghai, China) at $105^{\circ} \mathrm{C}$ for $6 \mathrm{~h}$. Dry weights of avocado pulp and seed were measured, and moisture contents $(\mathrm{g})$ were calculated from the differences between fresh and dry weight. The results are expressed as $\mathrm{g} / 100 \mathrm{~g}$ on a fresh weight basis. The measurements were performed in three replications per accession.

\subsubsection{Ash Assay}

A quartz crucible was placed in a muffle furnace at $550{ }^{\circ} \mathrm{C}$ for $0.5 \mathrm{~h}$, removed when the temperature had dropped below $200{ }^{\circ} \mathrm{C}$, and weighed after reaching room temperature, followed by repeated burning to attain a constant weight. The quartz crucible containing fresh avocado pulp or seed $(5 \mathrm{~g})$ was weighed, the samples were fully carbonized until smoke-free, placed in the muffle furnace at $550^{\circ} \mathrm{C}$ for $4 \mathrm{~h}$, and removed when the temperature was $<200^{\circ} \mathrm{C}$. The quartz crucible containing the ash was weighed again after cooling to room temperature. The results are displayed as $\mathrm{g} / 100 \mathrm{~g}$ on a fresh weight basis. The experiments were performed in triplicate for each accession. 


\subsubsection{Oil Content Assay}

Oil content was evaluated by the method of Villa-Rodríguez et al. (2011) with slight modifications. The avocado pulp and seed were dried and ground to a powder, and the dry powders $(5 \mathrm{~g})$ were transferred to a filter paper cylinder after addition of absolute ether at $50{ }^{\circ} \mathrm{C}$. The ratio of material to ether was 1:20. The filtered solutions were extracted until no more oil was present using a Soxhlet extractor. The extracts were then evaporated on a rotary evaporator and weighed. The results are expressed as $\mathrm{g} / 100 \mathrm{~g}$ on a fresh weight basis. The experiments were performed in triplicate for each avocado accession.

\subsubsection{Soluble Sugar Assay}

The total sugar content was determined using the colorimetric anthrone method described by Meyer and Terry (2008) with some modifications. Fresh avocado pulp and seed samples $(1 \mathrm{~g})$ were homogenized using a high-speed homogenizer with $5 \mathrm{ml}$ of ethanol $(80 \%)$ and transferred to $10 \mathrm{~mL}$ test tubes. The sample solutions were placed in a boiling water-bath for $10 \mathrm{~min}$ after decolorization with activated carbon. After cooling, the solutions were filtered and transferred to $25 \mathrm{~mL}$ triangular flasks, and the volumes were adjusted to $25 \mathrm{~mL}$ with ethanol (80\%). Filtrate samples $(1 \mathrm{~mL})$ were mixed with $5 \mathrm{~mL}$ anthrone reagent, shaken gently, and then placed in a boiling water-bath for $10 \mathrm{~min}$. After cooling, the absorbance was measured at $620 \mathrm{~nm}$ using a spectrophometer $(1 \mathrm{~mL}$ distilled water plus $5 \mathrm{~mL}$ anthrone reagent was used as the blank control). The total sugar content was calculated based on a calibration curve for glucose $\left(R^{2}=0.997\right)$. The soluble sugar content was expressed as $\mathrm{g} / 100 \mathrm{~g}$ fresh weight of sample. All measurements were performed in triplicate for each accession.

\subsubsection{Titratable Acidity Assay}

Fresh avocado pulp and seed (5 g) samples were homogenized using a high-speed homogenizer (Heidolph, Diax 900 , Germany). The samples were transferred to $50 \mathrm{~mL}$ triangular flasks, mixed with $30 \mathrm{~mL}$ of distilled water, and incubated in a water-bath at $80{ }^{\circ} \mathrm{C}$ for 90 min with constant stirring. After cooling, the solutions were transferred to $50 \mathrm{~mL}$ centrifuge tubes, centrifuged at $8000 \mathrm{rpm}$ for 10 minutes. The supernatants were transferred to $50 \mathrm{ml}$ calibrated flasks and the volumes were adjusted to $50 \mathrm{~mL}$ with distilled water. Titratable acidity was determined by titrating $15 \mathrm{ml}$ of avocado aqueous extracts with $0.01 \mathrm{M} \mathrm{NaOH}$, using phenolphthalein $(1 \%)$ as indicator. Distilled water was the blank control. Results were expressed as grams of tartaric acid per $100 \mathrm{~g}$ of sample, according to the methodology described by Vinha et al. (2013). The experiments were carried out in triplicate for each accession.

\subsubsection{Soluble Protein Assay}

Analyses of soluble protein contents were carried out using the Coomassie Blue staining method of Bradford (1976) with some modifications. Fresh avocado pulp and seed samples $(1 \mathrm{~g})$ were homogenized using a high-speed homogenizer in $5 \mathrm{ml}$ of distilled water and transferred to $25 \mathrm{~mL}$ triangular flasks. The volume was then adjusted to $25 \mathrm{~mL}$ with distilled water. After filtration, $0.1 \mathrm{~mL}$ samples of the filtrates were transferred to test tubes, $5 \mathrm{~mL}$ of the Coomassie Brilliant Blue G-250 reagent was added to each, and they were mixed completely. After incubation for $2 \mathrm{~min}$ at room temperature, the absorbance was measured at $595 \mathrm{~nm}$ using a Shimadzu UV-1800 spectrophotometer. Distilled water was the blank control. The soluble protein was calculated using $0-100 \mu \mathrm{g} / \mathrm{mL}$ and $1000 \mu \mathrm{g} / \mathrm{mL}$ calibration curves based on bovine serum albumin $\left(R^{2}=0.997\right)$. The soluble protein content was expressed as $\mathrm{g} / 100 \mathrm{~g}$ fresh weight of sample. All measurements were performed in triplicate for each accession.

\subsubsection{Fatty Acid Composition Assay}

Analyses of the fatty acid profiles were performed using the method of Villa-Rodríguez et al. (2011) with some modifications. The oils extracted from avocado pulp and seed $(40 \mu \mathrm{L})$ were saponified at $80{ }^{\circ} \mathrm{C}$ for $30 \mathrm{~min}$ after addition of $5 \mathrm{~mL} \mathrm{NaOH}-\mathrm{MeOH}(0.2 \mathrm{~mol} / \mathrm{L})$. After cooling, the solutions were mixed with $2.5 \mathrm{~mL} \mathrm{BF}-\mathrm{MeOH}$ (14\%) and incubated at $80{ }^{\circ} \mathrm{C}$ for $30 \mathrm{~min}$ to produce methyl esters of the fatty acids. Following this, $2 \mathrm{~mL}$ of saturated $\mathrm{NaCl}$ and $4 \mathrm{~mL} n$-hexane were added, and the resulting solutions were refluxed for $15 \mathrm{~min}$. The upper layers were then removed, filtered through $0.22 \mu \mathrm{m}$ membranes, and used for fatty acid GC-MS analyses.

The analyses were performed on an Agilent7890B-7000B GC-MS equipped with a DB-5MS (60 $\mathrm{m} \times 0.25 \mathrm{~mm}$ i.d., $0.25 \mu \mathrm{m}$ film thickness) column using helium $(1.2 \mathrm{~mL} / \mathrm{min})$ as the carrier gas. The oven temperature was programmed as follows: initial temperature of $100{ }^{\circ} \mathrm{C}$ held for $3 \mathrm{~min}$, increased to $180^{\circ} \mathrm{C}$ at $3{ }^{\circ} \mathrm{C} / \mathrm{min}$, held for 1 min, increased to $220^{\circ} \mathrm{C}$ at $1{ }^{\circ} \mathrm{C} / \mathrm{min}$, held for $1 \mathrm{~min}$, and finally increased to $280{ }^{\circ} \mathrm{C}$ at $5{ }^{\circ} \mathrm{C} / \mathrm{min}$ and held for 5 min. Injector and detector temperatures were $250{ }^{\circ} \mathrm{C}$ and $230{ }^{\circ} \mathrm{C}$, respectively. The mass spectrometer was operated in the electron impact mode at $70 \mathrm{eV}$ in the scan range of $35-400 \mathrm{~m} / \mathrm{z}$. The fatty acid methyl esters 
(FAMEs) were identified by comparing peaks retention times to those of commercial standards and by comparing the respective ion chromatograms with those reported in the NIST 2011 library. The FAMEs were quantified against methyl nonadecanoate that was added as an internal standard. Quantifications were evaluated from calibration curves of the respective FAMEs $\left(R^{2} \geq 0.995\right)$. FAMEs were expressed as $\mathrm{mg} / 100 \mathrm{~g}$ on a fresh weight basis. The experiments were carried out in triplicate for both avocado accessions.

\subsubsection{Mineral Elements Assay}

Avocado pulp and seeds were dried and ground to a powder. The dry powders $(0.5 \mathrm{~g})$ were transferred to $50 \mathrm{~mL}$ beakers containing $5 \mathrm{~mL}$ concentrated nitric acid and digested at a temperature of $140{ }^{\circ} \mathrm{C}$ for $1 \mathrm{~h}$ on an electric hot plate. Determination of $\mathrm{Na}, \mathrm{Mg}, \mathrm{K}, \mathrm{Ca}, \mathrm{Mn}, \mathrm{Fe}, \mathrm{Cu}$, and $\mathrm{Zn}$ in the previously mineralised samples was conducted in an AAnalyst 400 atomic absorption spectrometer (Perkin Elmer Ltd., Shanghai, China). Concentrated nitric acid was used as the blank control. Quantification was obtained from a calibration curve of certified reference materials $\left(R^{2} \geq 0.995\right)$. Mineral elements were expressed as $\mathrm{mg} / 100 \mathrm{~g}$ on a fresh weight basis. The experiments were performed in triplicate for both accessions.

\subsection{Quantification of Bioactive Compounds}

\subsubsection{Total Polyphenolic Assay}

Total phenolic content was determined based on the method of Villa-Rodríguez et al. (2011) with slight modifications. Dry powder residues of avocado pulp and seed ( $0.2 \mathrm{~g}$, after lipid removal) were dissolved in $5 \mathrm{~mL}$ ethanol $(50 \%)$, subjected to ultrasonic extraction for $15 \mathrm{~min}$, and centrifuged at $8000 \mathrm{rpm}$ for 10 minutes. The $0.1 \mathrm{~mL}$ extracts were transferred to centrifuge tubes, mixed with $3 \mathrm{~mL}$ distilled water, $0.25 \mathrm{~mL}$ Folin and Ciocalteau phenol reagent $(1 \mathrm{~N})$, and $0.75 \mathrm{~mL} \mathrm{Na}_{2} \mathrm{CO}_{3}(20 \%)$, and then diluted with distilled water to a volume of $5 \mathrm{~mL}$. After incubation for $30 \mathrm{~min}$ in the dark at room temperature, the absorbance was read at $760 \mathrm{~nm}$ using a Shimadzu UV-1800 spectrophotometer. Distilled water was used as the blank control. Total phenolic compounds were calculated using a calibration curve of gallic acid $\left(R^{2}=0.997\right)$ and displayed as gallic acid equivalents (mg $\mathrm{GAE} / 100 \mathrm{~g}$ on a fresh weight basis). The experiments were performed in triplicate for the two accessions.

\subsubsection{Tannin Assay}

Fresh avocado pulp and seed samples $(5 \mathrm{~g})$ were homogenized separately in $80 \mathrm{~mL}$ distilled water using a high-speed homogenizer (Heidolph, Diax 900, Germany), placed in a boiling water-bath for $30 \mathrm{~min}$, and then adjusted to a volume of $100 \mathrm{~mL}$ with distilled water. Subsamples $(5 \mathrm{~mL})$ of the solutions were transferred to centrifuge tubes and centrifuged at $8000 \mathrm{rpm}$ for 5 minutes. For the assays, $1 \mathrm{~mL}$ aliquots of the extracts were combined with $1 \mathrm{~mL} \mathrm{Na} 2 \mathrm{WO}_{4} \cdot 2 \mathrm{H}_{2} \mathrm{O}$ and $\mathrm{Na}_{2} \mathrm{MoO}_{4}$ mixture solution, $3 \mathrm{~mL} \mathrm{Na}_{2} \mathrm{CO}_{3}$, and $5 \mathrm{~mL}$ distilled water, and incubated for 2 hour in the dark at room temperature to allow for color development. The $0 \mathrm{mg} / \mathrm{L}$ sample was used as the blank control. Tannin content was measured spectrophotometrically on a Shimadzu UV-1800 spectrophotometer at $765 \mathrm{~nm}$. The values on the calibration curve were referred to total polyphenolic assay and displayed as gallic acid equivalents. The results are displayed as $\mathrm{mg} \mathrm{GAE} / 100 \mathrm{~g}$ on a fresh weight basis. The experiments were performed in triplicate.

\subsubsection{Total Flavonoid Assay}

Total flavonoid concentrations were determined by the method of Villa-Rodríguez et al. (2011) with some modifications. As in the polyphenol assay, dry powder residues of avocado pulp and seed $(0.2 \mathrm{~g}$, after lipid removal) were dissolved in $5 \mathrm{~mL}$ ethanol $(50 \%)$, extracted ultrasonically for $15 \mathrm{~min}$, and centrifuged at $8000 \mathrm{rpm}$ for 10 minutes. Aliquots of the extracts $(0.1 \mathrm{~mL})$ were transferred to centrifuge tubes, mixed with $2 \mathrm{~mL}$ distilled water and $0.15 \mathrm{~mL} \mathrm{NaNO} 2(5 \%)$, and incubated for $6 \mathrm{~min}$. After $0.15 \mathrm{~mL}$ of $\mathrm{AlCl}_{3} \cdot 6 \mathrm{H}_{2} \mathrm{O}(10 \%)$ was added, the extracts were allowed to stand for $1 \mathrm{~min}$, and $2 \mathrm{~mL}$ of $\mathrm{NaOH}(1 \mathrm{M})$ were then added. The volume was adjusted to $10 \mathrm{~mL}$ with distilled water. For the seed samples, $0.5 \mathrm{~mL}$ aliquots of the extracts were diluted with distilled water to $6 \mathrm{~mL}$, and the absorbance was determined at $510 \mathrm{~nm}$ with a Shimadzu UV-1800 spectrophotometer. Distilled water was used as the blank control. Total flavonoid concentrations were calculated using a calibration curve of rutin $\left(R^{2}=0.995\right)$ and expressed as rutin equivalents (mg RE/100 $\mathrm{g}$ on a fresh weight basis). The experiments were performed in triplicate.

\subsubsection{Ascorbic Acid Assay}

Ascorbic acid content was determined using the modified 2,6-dichlorophenolindophenol method (Franck et al., 2003). Samples of fresh avocado pulp and seed $(5 \mathrm{~g})$ were homogenized separately using a high-speed homogenizer (Heidolph, Diax 900, Germany) in $5 \mathrm{ml}$ of oxalic acid (2\%). The volume was adjusted to $100 \mathrm{~mL}$ with distilled water. The sample solutions were transferred to centrifuge tubes, centrifuged at $8000 \mathrm{rpm}$ for 10 minutes, and $10 \mathrm{~mL}$ aliquots of the extracts were titrated with 2,6-dichlorophenolindophenol. Oxalic acid (2\%) 
was used as the blank control. Ascorbic acid was expressed as $\mathrm{mg} / 100 \mathrm{~g}$ on a fresh weight basis. The experiments were performed in triplicate.

\subsubsection{Tocopheryl Acetate Assay}

Samples of fresh avocado pulp and seed $(5 \mathrm{~g})$ were homogenized using a high-speed homogenizer as described above for the moisture, acidity, and soluble protein assays. After addition of $50 \mathrm{~mL}$ ethanol $(95 \%), 10 \mathrm{~mL}$ ethyl ether, and $20 \mathrm{~mL} \mathrm{NaOH}$ solution $(50 \%)$, the solutions were transferred to $250 \mathrm{~mL}$ saponification flasks and saponified by refluxing in a boiling water bath for $30 \mathrm{~min}$. The saponification reactions were transferred to 250 $\mathrm{mL}$ separatory funnels and mixed with $40 \mathrm{~mL}$ distilled water and $50 \mathrm{~mL}$ ethyl ether. After shaking vigorously for $1 \mathrm{~min}$, the supernatants were transferred to $250 \mathrm{~mL}$ volumetric flasks, and the volumes were adjusted to $250 \mathrm{~mL}$ with ethyl ether. Samples $(5 \mathrm{~mL})$ of the extracts were heated at $90{ }^{\circ} \mathrm{C}$ in a water-bath until the flask contents were reduced almost to dryness. The end-products were dissolved in methanol to a final volume of $10 \mathrm{~mL}$. The absorbance at $284 \mathrm{~nm}$ was measured using a Shimadzu UV-1800 spectrophotometer. Methanol was used as the blank control. Tocopheryl acetate was expressed as $\mathrm{mg} / 100 \mathrm{~g}$ on a fresh weight basis. The experiments were performed in triplicate.

\subsubsection{Total Carotenoid Assay}

Fresh avocado pulp and seed samples $(5 \mathrm{~g})$ were homogenized using a high-speed homogenizer as described in the previous section. The volume was adjusted to $100 \mathrm{~mL}$ with petroleum ether. The sample solutions were filtered through sodium sulphate, transferred to $100 \mathrm{ml}$ volumetric flasks, and then diluted to $100 \mathrm{ml}$ with petroleum ether. After incubation for $24 \mathrm{~h}$ at room temperature, total carotenoid content was measured spectrophotometrically at $445 \mathrm{~nm}$ using a Shimadzu UV-1800 spectrophotometer. Petroleum ether was the blank control. The results are presented as $\beta$-carotene equivalents $(\mathrm{mg} / 100 \mathrm{~g}$ on a fresh weight basis). The experiments were carried out in triplicate.

\subsection{Statistical Analyses}

The data were analyzed using SPSS version 20.0 software (SPSS Inc., Chicago, IL, USA). The results were presented as the mean \pm standard deviation of three or nine measurements.

\section{Results and Discussion}

\subsection{Morphological Characteristics and Physicochemical Analyses}

Table 1 shows the morphological parameters of the fruits of two avocado accessions. The fruits of RN-7 are ovate, large in size $(505.56 \pm 39.09 \mathrm{~g})$, and are larger than those of many of the widely cultivated avocado varieties such as 'Hass', 'Fuerte', 'Gwen', and 'Lamb Hass', etc. (Gómez-López et al., 1999, 2002; Schaffer et al., 2012). While the fruits of RN-8 were pyriform and of medium size (336.67 $\pm 26.46 \mathrm{~g})$. The seeds of RN-7 and RN-8 were all of medium size $(50.90 \pm 9.08$ and $69.73 \pm 4.26 \mathrm{~g})$ and nearly spherical in shape. Others have reported the seed weight of more than thirty avocado cultivars from around the world from $26.54 \mathrm{~g}$ for Duke to 115.82 g for Ceniap 2 (Gómez-López et al., 1999, 2002; Rodríguez-Carpena et al., 2011; Galvão et al., 2014). This indicates that these two Chinese native avocado accessions had the medium-sized seeds in comparison with foreign avocado varieties. Lightness and chroma of RN-7 avocado fruit were greater than those of RN-8; however, the hue angle of RN-7 avocado fruit was the same as RN-8, which suggest that the degree of saturation and color intensity of RN-7 avocado fruit are higher than those of RN-8 avocado fruit, but peel color of RN-7 and $\mathrm{RN}-8$ were very similar. 
Table 1. Morphological characteristics and physicochemical parameters (mean value \pm standard deviation, $n=9$ ) of fruits of two Chinese avocado accessions

\begin{tabular}{lll}
\hline Morphological characteristic & RN-7 & RN-8 \\
\hline Fruit weight $(\mathrm{g})$ & $505.56 \pm 39.09$ & $336.67 \pm 26.46$ \\
Fruit length $(\mathrm{cm})$ & $12.30 \pm 0.50$ & $16.88 \pm 1.30$ \\
Fruit diameter $(\mathrm{cm})$ & $8.92 \pm 0.38$ & $6.91 \pm 0.31$ \\
Seed weight $(\mathrm{g})$ & $69.73 \pm 4.26$ & $50.90 \pm 9.08$ \\
Seed length $(\mathrm{cm})$ & $4.49 \pm 0.24$ & $5.90 \pm 0.60$ \\
Seed diameter $(\mathrm{cm})$ & $4.71 \pm 0.18$ & $4.23 \pm 0.22$ \\
$\mathrm{~L}^{*}$ & $45.27 \pm 2.35$ & $38.35 \pm 2.36$ \\
Hue $\left({ }^{\circ}\right)$ & $1.09 \pm 0.02$ & $1.09 \pm 0.04$ \\
Chroma $(\%)$ & $40.37 \pm 3.02$ & $31.01 \pm 4.66$ \\
\hline
\end{tabular}

Note. $\mathrm{L}^{*}=$ Luminance; Hue $\left({ }^{\circ}\right)=$ Hue angle.

\subsection{Nutritional Compositions Analyses}

The avocado pulp has a higher water and total lipid content than does the seed (Table 2), which is in agreement with previous studies (Rodríguez-Carpena et al., 2011; Vinha et al., 2013; Galvão et al., 2014). The total lipid contents in the pulp of RN-7 and RN-8 fruits were all $\leq 8 \%$, placing them in the group of varieties with low oil content, which are inferior to the widely grown 'Hass' cultivar (Gómez-López, 1999, 2002; Rodríguez-Carpena et al., 2011; Villa-Rodríguez et al., 2011; Dreher and Davenport, 2013). The pulp of RN-7 and RN-8 contains more soluble protein $(0.42 \mathrm{~g} / 100 \mathrm{~g})$, more than twice that measured in the seed in the present study (Table 2), although previous studies found that soluble protein levels in the pulp are lower than levels in the peel and seed (Rodríguez-Carpena et al., 2011; Vinha et al., 2013; Galvão et al., 2014). Comparable levels of ash differed between the pulp and the seed depending on the variety (Rodríguez-Carpena et al., 2011; Vinha et al., 2013; Galvão et al., 2014). Similarly, we found that comparisons of the ash content between the pulp and seed were the exact opposite for RN-7 and RN-8 (Table 2). The soluble sugar content and titratable acidity of the pulp were higher than in the seed, which agreed with the results of a previous study (Vinha et al., 2013). In addition, recent research has shown that soluble sugars may be the precursors of lipid synthesis in avocado fruit (Kilaru et al., 2015). This was supported in the present study, where we found that the higher the lipid content, the lower the soluble sugar levels in the pulp and seed of avocado fruit (Table 2). The contents of six mineral elements (sodium, potassium, calcium, iron, copper, and zinc) were higher in the seed than in the pulp, but two other mineral elements (magnesium and manganese) showed very small differences between the pulp and seed (Table 2). 
Table 2. Nutritional compositions (mean value \pm standard deviation, proximates for $\mathrm{g} / 100 \mathrm{~g} \mathrm{FW}$ and minerals for $\mathrm{mg} / 100 \mathrm{~g} \mathrm{FW}, n=3$ ) of pulp and seed of fruits of two Chinese avocado accessions

\begin{tabular}{|c|c|c|c|c|}
\hline \multirow{2}{*}{ Nutritional composition } & \multicolumn{2}{|c|}{ RN-7 } & \multicolumn{2}{|c|}{ RN-8 } \\
\hline & Pulp & Seed & Pulp & Seed \\
\hline \multicolumn{5}{|l|}{ Proximates } \\
\hline Moisture & $82.85 \pm 0.17$ & $69.61 \pm 0.20$ & $83.59 \pm 0.32$ & $69.71 \pm 0.38$ \\
\hline Ash & $0.52 \pm 0.00$ & $0.64 \pm 0.01$ & $0.74 \pm 0.01$ & $0.63 \pm 0.01$ \\
\hline Total lipid & $7.33 \pm 0.15$ & $1.40 \pm 0.04$ & $6.53 \pm 0.14$ & $3.18 \pm 0.17$ \\
\hline Soluble sugar & $0.56 \pm 0.02$ & $1.78 \pm 0.03$ & $0.72 \pm 0.05$ & $2.43 \pm 0.03$ \\
\hline Titratable acidity & $1.78 \pm 0.03$ & $2.57 \pm 0.08$ & $2.63 \pm 0.03$ & $2.87 \pm 0.03$ \\
\hline Soluble protein & $0.42 \pm 0.03$ & $0.19 \pm 0.02$ & $0.42 \pm 0.02$ & $0.16 \pm 0.01$ \\
\hline \multicolumn{5}{|l|}{ Minerals } \\
\hline Sodium & $0.52 \pm 0.04$ & $1.54 \pm 0.01$ & $0.47 \pm 0.04$ & $1.11 \pm 0.09$ \\
\hline Magnesium & $1.40 \pm 0.01$ & $1.41 \pm 0.06$ & $1.73 \pm 0.02$ & $1.83 \pm 0.03$ \\
\hline Potassium & $247.01 \pm 10.58$ & $336.45 \pm 25.24$ & $240.24 \pm 1.24$ & $310.95 \pm 0.64$ \\
\hline Calcium & $10.87 \pm 0.52$ & $18.51 \pm 0.76$ & $9.01 \pm 0.20$ & $14.32 \pm 0.47$ \\
\hline Manganese & $0.03 \pm 0.00$ & $0.05 \pm 0.00$ & $0.03 \pm 0.00$ & $0.03 \pm 0.00$ \\
\hline Iron & $0.91 \pm 0.03$ & $1.18 \pm 0.09$ & $0.80 \pm 0.11$ & $1.48 \pm 0.05$ \\
\hline Copper & $0.18 \pm 0.00$ & $0.35 \pm 0.00$ & $0.16 \pm 0.00$ & $0.33 \pm 0.03$ \\
\hline Zinc & $0.05 \pm 0.00$ & $0.07 \pm 0.00$ & $0.06 \pm 0.00$ & $0.10 \pm 0.00$ \\
\hline
\end{tabular}

\subsection{Fatty Acid Profiles Analyses}

The fatty acid compositions of the pulp and seed oils are presented in Table 3. Eight fatty acids were detected in the pulp and seeds of fruits of avocado accessions RN-7 and RN-8. The palmitic (C16:0), palmitoleic (C16:1), stearic (18:0), oleic (C18:1), and linoleic (18:2) acid contents of the pulp were higher than those in the seed. Myristic (C14:0) and arachic (C20:0) acid levels were higher in the seed, while the linolenic acid (C18:3) levels differed considerably between the two accessions. These results differed slightly from those reported previously, since Galvão et al. (2014) suggested that levels of oleic acid (C18:1) in the pulp and linoleic (18:2) in the seed were higher among the cultivars 'Fortuna', 'Collinson', and 'Barker'. Nevertheless, other fatty acids such as myristic (C14:0), palmitic (C16:0), palmitoleic (C16:1), stearic (18:0), and arachic (C20:0) acids showed different comparable levels between the pulp and seed among these three cultivars. The contents of palmitic (C16:0), oleic acid (C18:1), and linoleic (18:2) acids in the pulp of RN-7 and RN-8 avocado fruits all exceeded $1000 \mathrm{mg} / 100 \mathrm{~g}$ fresh weight, and represented the majority of the total fatty acids quantified. These results agree with those reported previously by other authors for avocado cultivars such as 'Hass' and 'Fuerte', etc. (Ozdemir \& Topuz, 2004; Meyer \& Terry, 2008, 2010; Villa-Rodríguez et al., 2011; Dreher \& Davenport, 2013; Donetti \& Terry, 2014; Galvão et al., 2014; Ferreyra et al., 2016; Pedreschi et al., 2016; Rohman et al., 2016). In all of them, more than $63 \%$ of total fatty acids (TFA) of the pulp and seed of avocado were unsaturated, the remaining were saturated $(37 \%)$ (Table 3$)$. Total unsaturated fatty acids ( $\Sigma$ UFA), total saturated fatty acids ( $\Sigma$ SFA), and TFA were all much higher in the pulp of two accessions than in the seed (Table 3). The ratios of $\Sigma$ UFA/ $\Sigma$ SFA were larger than 1.0 for the pulp and seed of two accessions, especially in the pulp of RN-8, which indicated that avocado could serve as a food supplement in the diet to decrease the level of cholesterol and fats, preventing the risk of cardiovascular disease (Richard et al., 2008). 
Table 3. Fatty acid compositions (mean value \pm standard deviation, $\mathrm{mg} / 100 \mathrm{~g} \mathrm{FW}, n=3$ ) of the pulp and seed oils obtained from fruits of two Chinese avocado accessions

\begin{tabular}{|c|c|c|c|c|}
\hline \multirow{2}{*}{ Fatty acids } & \multicolumn{2}{|c|}{$\mathrm{RN}-7$} & \multicolumn{2}{|c|}{$\mathrm{RN}-8$} \\
\hline & Pulp & Seed & Pulp & Seed \\
\hline \multicolumn{5}{|l|}{ Saturated fatty acids (SFA) } \\
\hline Myristic acid (C14:0) & $15.46 \pm 0.44$ & $28.01 \pm 1.00$ & $12.90 \pm 0.16$ & $25.92 \pm 1.17$ \\
\hline Palmitic acid (C16:0) & $2431.81 \pm 97.27$ & $288.07 \pm 29.22$ & $1727.92 \pm 6.73$ & $359.00 \pm 24.52$ \\
\hline Stearic acid $(18: 0)$ & $83.71 \pm 4.23$ & $44.92 \pm 1.81$ & $73.20 \pm 2.77$ & $46.31 \pm 2.00$ \\
\hline Arachic acid (C20:0) & $25.38 \pm 0.37$ & $40.59 \pm 0.11$ & $24.02 \pm 0.24$ & $40.62 \pm 0.15$ \\
\hline \multicolumn{5}{|c|}{ Mono-unsaturated fatty acids (MUFA) } \\
\hline Palmitoleic acid (C16:1) & $526.63 \pm 26.46$ & $53.99 \pm 4.30$ & $393.11 \pm 6.36$ & $48.32 \pm 5.52$ \\
\hline Oleic acid (C18:1) & $2090.11 \pm 169.83$ & $266.08 \pm 14.39$ & $1999.57 \pm 181.68$ & $174.51 \pm 10.41$ \\
\hline \multicolumn{5}{|c|}{ Poly-unsaturated fatty acids (PUFA) } \\
\hline Linoleic acid (18:2) & $1615.41 \pm 98.16$ & $420.23 \pm 6.78$ & $1481.21 \pm 15.94$ & $626.85 \pm 82.75$ \\
\hline Linolenic acid (C18:3) & $83.20 \pm 5.49$ & $74.37 \pm 4.70$ & $44.46 \pm 3.54$ & $61.30 \pm 5.49$ \\
\hline$\Sigma$ SFA & $2556.36 \pm 38.73$ & $401.59 \pm 12.19$ & $1838.04 \pm 9.9$ & $471.85 \pm 12.27$ \\
\hline$\Sigma$ UFA & $4315.35 \pm 84.65$ & $814.67 \pm 27.32$ & $3918.35 \pm 48.61$ & $910.98 \pm 26.05$ \\
\hline TFA & $6871.71 \pm 123.38$ & $1216.26 \pm 39.51$ & $5756.39 \pm 58.51$ & $1382.83 \pm 38.32$ \\
\hline$\Sigma \mathrm{UFA} / \Sigma \mathrm{SFA}$ & $1.69 \pm 0.02$ & $2.03 \pm 0.01$ & $2.13 \pm 0.02$ & $1.93 \pm 0.01$ \\
\hline
\end{tabular}

Note. $\Sigma \mathrm{SFA}=$ total unsaturated fatty acids; $\Sigma \mathrm{UFA}=$ total unsaturated fatty acids; TFA $=$ total fatty acids.

\subsection{Bioactive Compounds Analyses}

Remarkably, the total phenolic, flavonoid, and tannin contents of the seed were 10- to 40-fold greater than in the pulp (Table 4). Previous studies also found that total phenolic and flavonoid contents of the seed far exceeded those of the pulp, and these compounds possess strong in vitro antioxidant activity and antimicrobial potential (Hidalgo et al., 2010; Rodríguez-Carpena et al., 2011; Kosinska et al., 2012; Vinha et al., 2013). Therefore, the avocado seed, as a byproduct, could be an interesting and inexpensive raw material for a functional food ingredient or an antioxidant additive (Rodríguez-Carpena et al., 2011; Kosinska et al., 2012). Vinha et al. (2013) suggested that the ascorbic acid and total carotenoid contents of the seed are superior to those in the pulp. However, considering the contents of ascorbic acid and total carotenoids, we found that the highest values were in the pulp (Table 4). Tocopheryl acetate was not detected in the seed of either of the two accessions; however, tocopheryl acetate was present in almost the same amounts in the pulp and seed (Vinha et al., 2013).

Table 4. Bioactive constituents (mean value \pm standard deviation, $\mathrm{mg} / 100 \mathrm{~g} \mathrm{FW}, n=3$ ) present in the pulp and seed of fruits of two Chinese avocado accessions

\begin{tabular}{llllll}
\hline \multirow{2}{*}{ Bioactive constituents } & \multicolumn{2}{c}{ RN-7 } & & \multicolumn{2}{c}{ RN-8 } \\
\cline { 2 - 3 } \cline { 5 - 6 } & Pulp & Seed & & Pulp & Seed \\
\hline Total phenolics & $44.39 \pm 2.81$ & $685.58 \pm 13.45$ & & $109.39 \pm 5.29$ & $798.52 \pm 54.04$ \\
Flavonoids & $43.85 \pm 6.37$ & $1636.25 \pm 50.88$ & & - & $936.60 \pm 56.91$ \\
Tannin & $0.09 \pm 0.01$ & $2.02 \pm 0.04$ & & $0.05 \pm 0.01$ & $2.45 \pm 0.09$ \\
Ascorbic acid & $18.57 \pm 0.31$ & $10.03 \pm 0.00$ & & $17.15 \pm 1.28$ & $12.02 \pm 0.20$ \\
Tocopheryl acetate & $1.28 \pm 0.03$ & - & & $2.32 \pm 0.11$ & - \\
Total carotenoids & $2.14 \pm 0.18$ & $2.02 \pm 0.04$ & & $2.02 \pm 0.02$ & $1.98 \pm 0.05$ \\
\hline
\end{tabular}

\section{Conclusions}

This study is the first to characterize and evaluate the morphological characteristics and the contents of nutrients and bioactive constituents in fruits of two avocado cultivars grown in Hainan province, China. The pulp and seeds were thoroughly compared in fruits from cultivars RN-7 and RN-8. For the main nutrients, the highest lipid and soluble protein contents were found in the pulp, but total phenolics, flavonoids, and tannin concentrations in the seed were 10- to 40-fold higher than in the pulp. The pulp and seed of both avocado accessions were found to contain a variety of fatty acids with carbon chain lengths of C14, C16, C18, and C20 
and varying degrees of unsaturation. Relatively high levels of palmitic, oleic, and linoleic acids were present in the pulp.

\section{References}

Ashton, O. B. O., Wong, M., \& McGhie, T. K. (2006). Pigments in avocado tissue and oil. Journal of Agricultural Food Chemistry, 54, 10151-10158. http://dx.doi.org/10.1021/jf061809j

Bradford, M. M. (1976). A rapid and sensitive method for the quantitation of microgram quantities of protein utilizing the principle of protein-dye binding. Analytical Biochemistry, 72, 248-254. http://dx.doi.org/ 10.1016/0003-2697(76)90527-3

Chen, G. L., Chen, S. G., Zhao, Y. Y., Luo, C. X., Li, J., \& Gao, Y. Q. (2014). Total phenolic contents of 33 fruits and their antioxidant capacities before and after in vitro digestion. Industrial Crops and Products, 57, 150-157. http://dx.doi.org/10.1016/j.indcrop.2014.03.018

Donetti, M., \& Terry, L. A. (2014). Biochemical markers defining growing area and ripening stage of imported avocado fruit cv. Hass. Journal of Food Composition and Analysis, 34, 90-98. http://dx.doi.org/10.1016/ j.jfca.2013.11.011

Dreher, M. L., \& Davenport, A. J. (2013). Hass avocado composition and potential health effects. Critical Reviews in Food Science and Nutrition, 53, 738-750. http://dx.doi.org/10.1080/10408398.2011.556759

Ferreyra, R., Selles, G., \& Saavedra, J. (2016). Identification of pre-harvest factors that affect fatty acid profiles of avocado fruit (Persea americana Mill) cv. 'Hass' at harvest. South African Journal of Botany, 104, 15-20. http://dx.doi.org/10.1016/j.sajb.2015.10.006

Franck, C., Baetens, M., Lammertyn, J., Scheerlinck, N., Davey, M. W., \& Nicola, B. M. (2003). Ascorbic acid mapping to study core breakdown development in "Conference" pears. Postharvest Biology and Technology, 30, 133-142. http://dx.doi.org/10.1016/S0925-5214(03)00108-X

Galvão, M. D. S., Narain, N., \& Nigam, N. (2014). Influence of different cultivars on oil quality and chemical characteristics of avocado fruit. Food Science and Technology, Campinas, 34, 539-546. http://dx.doi.org/ $10.1590 / 1678-457 x .6388$

Giraldoa, L., \& Moreno-Piraján, J. C. (2012). Lipase supported on mesoporous materials as a catalyst in the synthesis of biodiesel from Persea americana mill. oil. Journal of Molecular Catalysis B: Enzymatic, 77, 32-38. http://dx.doi.org/10.1016/j.molcatb.2012.01.001

Gómez-López, V. M. (1999). Characterization of avocado (Persea americana Mill.) varieties of low oil content. Journal of Agricultural Food Chemistry, 47, 2707-2710. http://dx.doi.org/10.1021/jf981206a

Gómez-López, V. M. (2002). Fruit characterization of high oil content avocado varieties. Scientia Agricola, 59, 403-406. http://dx.doi.org/10.1590/S0103-90162002000200030

He, G. X. (2012). The situation and developing prospect of avocado research and production in Guangxi. Journal of Guangxi Vocational and Technical College, 5, 1-6.

Hidalgo, M., Sánchez-Moreno, C., \& Pascual-Teresa, S. (2010). Flavonoid-flavonoid interaction and its effect on their antioxidant activity. Food Chemistry, 121, 691-696. http://dx.doi.org/10.1016/j.foodchem.2009.12.097

Hurtado-Fernandez, E., Carrasco-Pancorbo, A., \& Fernandez-Gutierrez, A. (2011). Profiling LC-DAD-ESI-TOF MS method for the determination of phenolic metabolites from avocado (Persea americana). Journal of Agricultural Food Chemistry, 59, 2255-2267. http://dx.doi.org/10.1021/jf104276a

Hurtado-Fernandez, E., Pacchiarotta, T., Mayboroda, O. A., Fernandez-Gutierrez, A., \& Carrasco-Pancorbo, A. (2014). Quantitative characterization of important metabolites of avocado fruit by gas chromatography coupled to different detectors (APCI-TOF MS and FID). Food Research International, 62, 801-811. http://dx.doi.org/10.1016/j.foodres.2014.04.038

Hurtado-Fernandez, E., Pacchiarotta, T., Mayboroda, O. A., Fernandez-Gutierrez, A., \& Carrasco-Pancorbo, A. (2015). Metabolomic analysis of avocado fruits by GC-APCI-TOF MS: effects of ripening degrees and fruit varieties. Analytical and Bioanalytical Chemistry, 407, 547-555. http://dx.doi.org/10.1007/s00216014-8283-9

Kilaru, A., Cao, X., Dabbs, P. B., Sung, H. J., Rahman, M. M., Thrower, N., .. Ohlrogge, J. B. (2015). Oil biosynthesis in a basal angiosperm: transcriptome analysis of Persea Americana mesocarp. BMC Plant Biology, 15, 203. http://dx.doi.org/10.1186/s12870-015-0586-2 
Kosinska, A., Karamac, M., Estrella, I., Hernandez, T., Bartolome, B., \& Dykes, G. A. (2012). Phenolic compound profiles and antioxidant capacity of Persea americana Mill. peels and seeds of two varieties. Journal of Agricultural Food Chemistry, 60, 4613-4619. http://dx.doi.org/10.1021/jf300090p

Meyer, M. D., \& Terry, L. A. (2008). Development of a rapid method for the sequential extraction and subsequent quantification of fatty acids and sugars from avocado mesocarp tissue. Journal of Agricultural Food Chemistry, 56, 7439-7445. http://dx.doi.org/10.1021/jf8011322

Meyer, M. D., \& Terry, L. A. (2010). Fatty acid and sugar composition of avocado, cv. Hass, in response to treatment with an ethylene scavenger or 1-methylcyclopropene to extend storage life. Food Chemistry, 121, 1203-1210. http://dx.doi.org/10.1016/j.foodchem.2010.02.005

Ozdemir, F., \& Topuz, A. (2004). Changes in dry matter, oil content and fatty acids composition of avocado during harvesting time and post-harvesting ripening period. Food Chemistry, 86, 79-83. http://dx.doi.org/10.1016/j.foodchem.2003.08.012

Papademetriou, M. K. (2013). Avocado Production in Asia and the Pacific. Bangkok, BK: FAO Publisher.

Pedreschi, R., Hollak, S., Harkema, H., Otma, E., Robledo, P., Somhorst, D., ... Defilippi, B. G. (2016). Impact of postharvest ripening strategies on 'Hass' avocado fatty acid profiles. South African Journal of Botany, 103, 32-35. http://dx.doi.org/10.1016/j.sajb.2015.09.012

Reddy, M., Moodley, R., \& Jonnalagadda, S. B. (2012). Fatty acid profile and elemental content of avocado (Persea americana Mill.) oil effect of extraction methods. Journal of Environmental Science and Health, Part B, 47, 529-537. http://dx.doi.org/10.1080/03601234.2012.665669

Richard, D., Kefi, K., Barbe, U., Bausero, P., \& Visioli, F. (2008). Polyunsaturated fatty acids as antioxidants. Pharmacological Research, 57, 451-455. http://dx.doi.org/10.1016/j.phrs.2008.05.002

Rodríguez-Carpena, J. G., Morcuende, D., Andrade, M. J., Kylli, P., \& Estevez, M. (2011). Avocado (Persea americana Mill.) phenolics, in vitro antioxidant and antimicrobial activities, and inhibition of lipid and protein oxidation in porcine patties. Journal of Agricultural Food Chemistry, 59, 5625-5635. http://dx.doi.org/10.1021/jf1048832

Rohman, A., Windarsih, A., Riyanto, S., Sudjadi, G., Ahmad, S. A. S., Rosman, A. S., \& Yusof, F. M. (2016). Fourier transforms infrared spectroscopy combined with multivariate calibrations for the authentication of avocado oil. International Journal of Food Properties, 19, 680-687. http://dx.doi.org/10.1080/10942912. 2015.1039029

Schaffer, B., Wolstenholme, B. N., \& Whiley, A. W. (2012). The Avocado: Botany, Production and Uses (2nd ed.). Croydon, CD: CPI Group (UK) Ltd.

Villa-Rodríguez, J. A., Molina-Corral, F. J., Ayala-Zavala, J. F., Olivas, G. I., \& Gonzalez-Aguilar, G. A. (2011). Effect of maturity stage on the content of fatty acids and antioxidant activity of 'Hass' avocado. Food Research International, 44, 1231-1237. http://dx.doi.org/10.1016/j.foodres.2010.11.012

Vinha, A. F., Moreira, J., \& Barreira, S. V. P. (2013). Physicochemical parameters, phytochemical composition and antioxidant activity of the Algarvian avocado (Persea americana Mill.). Journal of Agricultural Science, 5, 100-109. http://dx.doi.org/10.5539/jas.v5n12p100

Zhang, L., Zhang, D. S., \& Liu, K. D. (2015). Environmental analysis and countermeasures for industrial development of Hainan avocado. Chinese Journal of Agricultural Resources and Regional Planning, 36, 78-84.

\section{Copyrights}

Copyright for this article is retained by the author(s), with first publication rights granted to the journal.

This is an open-access article distributed under the terms and conditions of the Creative Commons Attribution license (http://creativecommons.org/licenses/by/4.0/). 